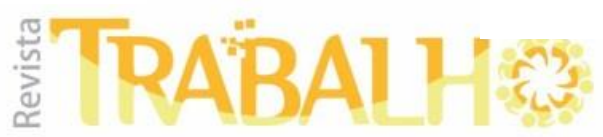

(En)Cena

\title{
PSICODINÂMICA DO TRABALHO E ATIVIDADE PASTORAL
}

\author{
Work Psychodynamics and pastoral activity \\ Psychodynamique du Travail et Activité Pastorale \\ Psicodinámica del Trabajo y Actividad Pastoral
}

\begin{abstract}
Osmar Oliveira Alves dos Santos ${ }^{1}$
Psicólogo graduado na Universidade Católica de Brasília (UCB), Bacharel em Teologia pela Faculdade Evangélica de Brasília (FE), Especialista em Psicanálise Clínica pela Associação Nacional de Psicanálise Clínica (ANPC), Especialista em Gestão Eclesiástica pela Faculdade Evangélica de Brasília (FE)
\end{abstract}

\begin{abstract}
Psicóloga (UnB), Es pecialista em Bioética (UnB), Mestra em Psicologia Social do Trabalho e das Organizações (PSTO-UnB), Doutoranda em Psicologia Clínica e Cultura da Universidade de Brasília (PsiCC - UnB) e exdocente do Curso de Psicologia da Universidade Católica de Brasília
\end{abstract}

Emilio Peres Facas 3

Colaborador do Programa de Pós-Graduação em Psicologia Social, do Trabalho e das Organizações (UnB). Psicólogo, Doutor em Psicologia Social, do Trabalho e das Organizações pela Universidade de Brasília com período sanduíche na UniversitéCatholique de Louvain. Coordenador do Laboratório de Psicodinâmica e Clínica do Trabalho - LPCT/UnB.

\section{Resumo}

Utilizando a Psicodinâmica do Trabalho como fundamento teórico, o presente estudo objetivou investigar as vivências de prazer-sofrimento no exercício do trabalho pastoral. Seus objetivos específicos foram: conhecer a organização do trabalho pastoral; investigar as estratégias de mediação do sofrimento dos pastores no exercício da profissão; e investigar se há reconhecimento do trabalho pastoral. Esta pesquisa foi realizada com quinze pastores de igrejas evangélicas de Brasilia, Distrito Federal, Brasil. A coleta de dados se deu por meio da realização de entrevistas semiestruturadas individuais, cujas falas foram analisadas por meio da técnica da Análise de Núcleos de Sentido. Como resultados, encontrou-se satisfação e identificação com as atividades pastorais, mas também excesso de trabalho. Há também falta de reconhecimento do trabalho pastoral por parte de alguns membros e/ou fieis, fatores que são minimizados pelo uso de estratégias de defesa. Não foi encontrado o uso de mobilização subjetiva. Apesar da ausência de afastamentos médicos recentes, o trabalho pastoral conduz ao adoecimento físico, psíquico e social.

Palavras-chave:psicologia do trabalho, psicodinâmica do trabalho, prazer-sofrimento, reconhecimento, atividade pastoral
Abstract
The aim of this study was to investigate pleasure-suffering experiences of evangelical church leaders in Brasilia-Brazil under the theoretical perspective of Work Psychodynamic. Specifically, the goals of the study were: to understand work organization; to investigate the strategies to mediate the suffering experience; and to evaluate presence of recognition related to work. Sample was composed by fifteen church leaders in which there were applied individual semi-structured interviews. As results, it was found that participants feel satisfied with their job and identify with tasks, despite strong overcharge of work and lack of recognition. In order to deal with those suffering experiences, church leaders run over

\footnotetext{
1 psicologoosmar@y ahoo.com.br

2 naclau@gmail.com

3 emilio@unb.br
} 
defense strategies and do not use mobilization to change work organization. Despite the fact they have not let work in the past twelve months to treatillness, participant are affected by physical, psychological, and social damages related to work.

Keywords: Work Psychology, Pleasure-suffering; Work Psychodynamic; Recognition, pastoral work.

Résumé

S'appuyant sur la psychodynamique du travail en tant que fondement théorique, la présente étude visait à examiner les expériences de souffrance de plaisir dans l'exercice du travail pastoral. Ses objectifs spécifiques étaient: connaître l'organisation de la pastorale; étudier des stratégies pour atténuer les souffrances des pasteurs dans l'exercice de leur profession; et rechercher s'il existe une reconnaissance du travail pastoral. Cette recherche a été réalisée avec quinze pasteurs d'églises évangéliques du Brasilia-Brasil. La collecte des données a été réalisée au moyen d'entretiens individuels semi-structurés, dont les discours ont été analysés à l'aide de la technique d'analyse des noyaux de sens. En conséquence, nous avons trouvé satisfaction et identification aux activités pastorales, mais aussi au surmenage. Il existe également un manque de reconnaissance du travail pastoral par certains membres et / ou fidèles, des facteurs minimisés par l'utilisation de stratégies de défense. L'utilisation de la mobilisation subjective n'a pas été trouvée. Malgré l'absence récente de congé de maladie, le travail pastoral conduit à des maladies physiques, psychiques et sociales.

Mots clés: Psychologie critique du travail;Psychodynamique du travail;Souffrance-plaisir; Reconnaissance;Activité pastorale.

\section{Resumen}

Teniendo la Psicodinámica del Trabajo como fundamento teórico, el presente estudio se propuso investigar las vivencias de placer-sufrimiento en el ejercicio del trabajo pastoral. Sus objetivos específicos fueron: conocer la organización del trabajo pastoral; investigar las estrategias de mediación del sufrimiento de los pastores en el ejercicio de la profesión; e investigar si hay reconocimiento del trabajo pastoral. Esta investigación fue realizada con quince pastores de iglesias evangélicas de BrasiliaBrasil. Los datos han sido recolectados por medio de la realización de entrevistas semiestructuradas individuales, y el análisis se dio con la utilización la técnica del Análisis de Núcleos de Sentido. Como resultados, se encontró satisfacción e identificación con las actividades pastorales, pero también exceso de trabajo. Hay también falta de reconocimiento del trabajo pastoral por parte de algunos miembros y / o fieles, cuy os factores son minimizados por el uso de estrategias de defensa. No se encontró el uso de la movilización subjetiva. A pesar de la ausencia de licencias médicas recientes, el trabajo pastoral conduce la enfermedad físico, psíquica y social.

Palabras clave: Psicología crítica deltrabajo; Psicodinámica del trabajo; Placer-sufrimiento en el trabajo; Reconocimiento; Actividad pastoral

\section{Introdução}

Nas últimas décadas, o segmento evangélico no Brasil vem crescendo e se fortalecendo muito rapidamente. A partir dos dados divulgados pelo Censo de 1991 (IBGE, 1992), eram 13.189.283 as pessoas que se declararam evangélicas no país, o que representava cerca de $9 \%$ da população à época. Já o Censo do ano 2000 (IBGE, 2003) mostrou que o número de evangélicos dobrou nesse espaço de tempo, passando a ser de 26.184.942 pessoas, o que representava mais de $15 \%$ da população brasileira naquele ano. O Censo de 2010 (IBGE, 2012) mostra que o número de evangélicos quadriplicou em quatro 
décadas, saltando de 5,2\% em 1970 para 22,2\% da população em 2010.

O crescimento da religião evangélica carrega consigo, dentre seus muitos aspectos, a notoriedade da função pastoral. As várias transformações sociais, políticas e dogmáticas percebidas no campo evangélico, oriundas do crescimento numérico dos fiéis e do aumento de sua visibilidade fizeram com que o trabalho de sua liderança também sofresse modificações: o pastor do século XXI não é apenas mais um pregador dominical itinerante, mas alguém que assume, no exercício de suas funções, os papéis de líder comunitário, político, psicólogo, advogado, doutor, palestrante, gerente, administrador, etc. (Silva, 2004).

Segundo a Classificação Brasile ira de Ocupações do Ministério do Trabalho e Emprego - CBO (MTE, 2012), a atividade dos pastores evangélicos encontra-se desta forma descrita:

"Realizam liturgias, celebrações, cultos e ritos; dirigem e administram comunidades; formam pessoas segundo preceitos religiosos das diferentes tradições; orientam pessoas; realizam ação social junto à comunidade; pesquisam a doutrina religiosa; transmitem ensiname nto $\mathrm{s}$ religiosos; praticam vida contemplativa e meditativa; preservam a tradição e, para isso, é essencial o exercício contínuo de competências pessoais específicas". Estudar as vivências de prazersofrimento no exercício da atividade pastoral revela-se importante, pois essa atividade se assemelha às demais profissões, principalmente no que tange à organização, às condições e a outros elementos do contexto de trabalho. As similaridades também dizem respeito ao próprio indivíduo trabalhador, uma vez que os líderes religiosos são tão humanos, falhos e vulneráveis quanto qualquer outro profissional (Silva, 2004).

Outro fator relevante do trabalho do pastor relaciona-se à questão vocacional de sua atividade. Para Weber (1967), a vocação que se manifesta no trabalho do líder religioso é a única maneira que os mesmos acreditam possuir para viverem aceitáveis por Deus. Trabalhar como líder religioso é aceitar a atividade como uma vocação, principalmente quando se percebe a transcendentalidade, que é a crença de ter sido "chamado por Deus". Não se trata, portanto, de uma escolha, mas de uma aceitação.

O referencial teórico escolhido não abrange apenas a investigação de aspectos materiais e normativos do trabalho, mas, principalmente, as questões subjetivas do 
trabalhador que mais se sobressaem quando de sua relação com o trabalho, motivo pelo qual se considerou relevante investigar $\mathrm{o}$ uso da subjetividade e de recursos psicológicos desses trabalhadores para lidar com as demandas advindas de suas funções. Para tanto, foi escolhido como referencial teórico a Psicodinâmica do Trabalho, a qual apresenta-se como uma possibilidade teórica e metodológica de investigação e compreensão das relações e inter-relações entre trabalho e saúde.

Por volta da metade do século passado, as poucas pesquisas que relacionavam o trabalho à saúde mental dos trabalhadores tinham como focos principa is a detecção, identificação e descrição das doenças mentais causadas pelo trabalho, o que 'tornava perceptível uma profunda relação dos modelos médicos clássicos com a psicopatologia do trabalho" (Dejours, 1996). Esse cenário começou a apresentar sinais de transição a partir dos trabalhos conduzidos por Dejours, cujos resultados acabaram por redefinir o objeto de estudo da psicopatologia do trabalho. Seus estudos iniciais nessa área eram centrados em pesquisas sobre o sofrimento psíquico no trabalho, buscando sua origem e as transformações resultantes do confronto entre 0 funcionamento psíquico do trabalhador e a organização do trabalho (Freitas, 2006), que era definida como a divisão do trabalho, o conteúdo da tarefa, o sistema hierárquico, as modalidades de comando, as relações de poder, as questões de responsabilidade, etc. (Dejours, 1992).

Com base em suas descobertas, Dejours propõe, então, um novo modelo de estudo mais dinâmico da psicopatologia do trabalho, superando o modelo causalista de detecção, identificação e descrição das doenças mentais específicas do trabalho. Nessa nova área, agora identificada como "Psicodinâmica do Trabalho" o foco recai sobre a compreensão de como os trabalhadores encontram saúde no trabalho mesmo experienciando situações de sofrimento que a priori também poderiam levar ao adoecimento (Dejours, Abdoucheli \& Jayet, 1994).

\section{A Psicodinâmica do Trabalho} apresenta três fases distintas. A primeira fase situa-se na década de 80 com estudos que versavam, ainda, sobre o sofrimento psíquico, sua origem e transformações. Nessa fase, investigaram-se a dinâmica dos sofrimentos e as estratégias de defesa desenvolvidas pelos trabalhadores. $\mathrm{Na}$ segunda fase, que permaneceu até o início da década de 90 , os estudos investigaram de que forma $\mathrm{o}$ trabalhador vivencia uma realidade prazerosa na sua relação com o trabalho e por fim, a partir dos anos 90, a terceira fase tem seu enfoque no trabalho como lócus de construção de identidade do trabalhador e a investigação sobre a dinâmica do reconhecimento das vivências 
de prazer e sofrimento frente às novas estruturas de organização do trabalho (Antloga \& Mendes, 2009).

Os primeiros resultados dos estudos de Dejours demonstram que do trabalho decorrem vivências de prazer e/ou de sofrimento, as quais se expressam por meio de sintomas específicos relacionados tanto ao contexto socioprofissional como à própria estrutura de personalidade do trabalhador (Mendes, 1994).

Conforme Dejours (1987 apud MENDES 1994):

"A organização do trabalho exerce sobre o homem uma ação específica, cujo impacto é o aparelho psíquico. Em certas condições emerge um sofrimento que pode ser atribuído ao choque entre uma história individual, portadora de projetos, de esperança e de desejos e uma organização que os ignora" (pág. 99).

Todo trabalho pressupõe uma carga psíquica resultante da confrontação do desejo do trabalhador com a realidade da organização do trabalho. Quando o trabalho não oferece espaço para articulações entre os desejos do trabalhador e a realidade,provoca o bloqueio ou acúmulo da energia psíquica, resultando em tensão e sofrimento. Entretanto, quando o trabalho permite um funcionamento psíquico sem pressões extremadas, proporciona uma redução dessa carga, tornando-se fonte de gratificação e prazer (Antloga \& Mendes, 2009).

O objetivo da Psicodinâmica do Trabalho é estudar não apenas as relações entre condutas e comportamentos dos trabalhadores com as vivências de prazer e sofrimento, mas sua relação com a organização do trabalho, fonte de pressões, dificuldades e desafios, e as relações sociais envolvidas (Dejours, Abdoucheli \& Jayet, 1994). O que importa para a Psicodinâmica do Trabalho é conseguir compreender como os trabalhadores mantêm um equilíbrio psíquico, mesmo estando submetidos a condições e organização de trabalho desestruturantes e provocadoras de sofrimentos. As condições do trabalho assim como a organização do trabalho podem exercer influências diretas à saúde física e/ou psíquica do trabalhador (Dejours 1993 apud Mendes, 2007).

\section{Trabalho}

O trabalho é um dos definidores do ser humano, pois permite sua realização pessoal, sua inserção do mundo e a construção da sua identidade social. É a partir do trabalho que o homem entra em contato com a realidade social, transformando-a e passa a ser transformado por ela. O trabalho é um dos caminhos para 
a felicidade e confirmação da existência humana (Freud, 1930 apud Silva, 2004).

O trabalho na psicodinâmica do trabalho é visto como o lugar de descarga psíquica da energia do trabalhador, oferecendo um caminho pelo qual o sujeito reconhece sua identidade, por meio do fazer. Assim, o trabalho torna-se um meio para satisfações concretas e simbólicas do trabalhador (Antloga \& Mendes, 2009).

O trabalho é fonte de prazer, de felicidade, de construção, mas também de repetição, de alienação, de sofrimento, revelando seu caráter ambivalente. Pode causar infelicidade, doença mental, mas em contrapartida não deixa de ser mediador de auto-realização, sublimação, subjetivação, saúde e mudança social (Silva, 2004). Essa possibilidade do trabalho proporcionar tanto prazer quanto sofrimento provoca a necessidade de se encontrar um sentido no próprio trabalho, já que o trabalho assume um sentido positivo quando é realizado de forma eficiente e conduz o trabalhador a algum resultado importante para si e para a sociedade; quando satisfaz e permite aprendizagem, autonomia, criatividade e responsabilidade; quando é moralmente aceito; quando é fonte de experiências satisfatória nas relações humanas estabelecidas, fortalecendo um sentimento de vinculação; quando garante segurança e autonomia e mantém o trabalhador adequadamente ocupado, (Morin, 2001 apud Silva, 2004).

Pode-se, assim, afirmar, que a nobre finalidade do trabalho é a própria sobrevivência física, psicológica e social do trabalhador (Ferreira \& Mendes, 2003).

\section{Organização do Trabalho}

A organização do trabalho compreende a divisão de homens e a divisão de tarefas. A divisão de homens refere-se à divisão hierárquica das pessoas que se relacionam no ambiente de trabalho, mobilizando sentimentos afetivos como amor, ódio e amizade. Já a divisão de tarefas se refere à divisão do conteúdo do trabalho entre as pessoas, o modo operatório prescrito, o que remete ao sentido e o interesse do trabalho para o sujeito (Dejours, 1992).

Definiu-se como organização do trabalho:

“... a divisão do trabalho, o conteúdo da tarefa (na medida em que ele dela deriva), o sistema hierárquico, as modalidades de comando, as relações de poder, as questões de responsabilidade etc" (Dejours, 1992, pág. 25).

A organização do trabalho compreende conceitos relacionados às normas, métodos, modificações e improvisações adotadas pelos trabalhadores 
para lidar com as dificuldades relacionadas à sua atividade laboral. Dentre outros motivos, a compreensão da organização do trabalho é importante para a psicodinâmica do trabalho, pois possibilita perceber o distanciamento entre trabalho real e trabalho prescrito, uma vez que este é descrito e exigido pela organização, enquanto aquele contempla o uso de aspectos subjetivos do trabalhador (Dejours, 2004). Essa exposição revela a necessidade de esclarecer, de modo mais detalhado, a distinção entre trabalho prescrito e o trabalho real.

O trabalho prescrito corresponde ao que antecede a execução da tarefa, sendo este um registro que satisfaz a necessidade de orientação, burocratização e fiscalização. Este geralmente se encontra normatizado em manuais de trabalho, instrução formal do que é a tarefa, regras de procedimento operacionais, etc. É fonte de reconhecimento e de punição - a última para quem não obedece. Já o trabalho real não se limita às prescrições, mas se define no próprio momento da execução. É tudo aquilo que não está previsto, porque não é o prescrito que define o trabalho, mas sim, a ação real do trabalhador, que deve engajar recursos para além da norma para cumprir com as exigências que the são colocadas pelo trabalho (Dejours, 2004).

Como as pressões da organização do trabalho constituem-se fonte de sofrimento para os trabalhadores, estes lançam mão de seu aparato psíquico para acessar recursos mentais individuais e, assim, ajustar novas maneiras de realizar seu trabalho de forma criativa e prazerosa, que vai além do simples responder a determinações. No espaço entre o prescrito e o real é que nasce o sofrimento: quando o trabalhador se depara com uma situação não prevista e que precisa ser resolvida, ele lança mão de sua criatividade para solucioná-la e encontrar, assim, prazer no trabalho (Dejours, 1999).O sofrimento é próprio, inerente ao trabalho, não podendo ser totalmente eliminado desse processo (Dejours, 2004). O sofrimento levará o sujeito a um estado de luta contra as forças (ligadas à organização do trabalho) que o empurram em direção à doença mental (Dejours, Abdoucheli \& Jayet, 1994).

O sofrimento psíquico do trabalhador caracteriza-se quando, no ambiente de trabalho, os sujeitos experienciam de forma inconsciente, individual e/ou compartilhada situações angustiantes mobilizadas pelo confronto entre o seu desejo e a organização do trabalho. Já as vivências de prazer somente são alcançadas quando os trabalhadores estiverem imbricados em um ambiente que promova o reconhecimento, a realização, a liberdade e a valorização do trabalho, uma vez que, dessa forma, podem obter 
satisfação de suas necessidades (Ferreira \& Mendes, 2003).

Estudos confirmam que a falta de reconhecimento da profissão ou do trabalho realizado é fonte de sofrimento psíquico e que a dinâmica do reconhecimento, que é fonte de prazer, origina-se a partir dos pares, hierarquia, clientes/usuários ou amigos e familiares. Tem função importante na relação saudável com $\mathrm{o}$ trabalho $\mathrm{e}$ na transformação do sofrimento patogênico em criativo, pois permite a ocorrência de um processo de reapropriação que extrapola a ação de resistir ao sofrimento e ao adoecimento, possibilitando a construção de um estado de saúde (Mendes \& Morrone, 2010). Nesse sentido, faz-se também importante investigar se há reconhecimento no trabalho de profissionais de diferentes áreas de atuação, visto este ser considerado um dos constituintes da saúde do trabalhador.

\section{A Psicodinâmica do Trabalho} também preocupa-se em compreender os "mecanismos de defesa" que os trabalhadores lançam mão para não adoecerem dentro das organizações, entendendo a normalidade como mecanismo de regulação ou equilíbrio entre, de um lado, as estratégias de defesa psíquicas organizadas e desenvolvidas pelos trabalhadores e, do outro, as situações desagradáveis causadoras de sofrimento e desestrutura pessoal (Dejours, 1996).
Diante da situação de sofrimento, o trabalhador pode trilhar por dois caminhos: o da saúde ou do adoecimento. Quando ele encontra vias de superar o sofrimento, e então o enfrenta de modo adequado, segue na direção da saúde. As estratégias de enfrentamento mais comuns são o uso de defesas e a mobilização subjetiva. Caso elas falhem e o trabalhador não encontre meios de ressignificar o sofrimento, ele sucumbirá em termos de saúde, encontrando o adoecimento (Dejours, 1996).

Quando expostos ao sofrimento no trabalho, os sujeitos podem desenvolver estratégias defensivas individuais ou coletivas de defesa para se protegem do sofrimento suscitado pelas pressões da organização do trabalho (Ferreira \& Mendes, 2003). A utilização de defesas visa evitar a dor que o sofrimento impõe ao trabalhador (Mendes \& Morrone, 2002). Surge, assim, um paradoxo, pois essas estratégias defensivas protegem os sujeitos de vivenciar sofrimento no trabalho, mas, ao mesmo tempo, favorecem a alienação dos trabalhadores, dificultando com que haja um maior contato entre eles e real condição da organização do seu trabalho (Dejours, Abdoucheli \& Jayet, 1994).

A mobilização subjetiva é uma fonte de vivência de prazer no trabalho, identificad a como um recurso utilizado pelo trabalhador para lidar com o sofrimento, e que se diferencia das estratégias de defesa 
porque demanda a ressignificação do sofrimento, ao invés de minimizá-lo ou negá-lo (Dejours, 2004 apud Mendes, 2007). Por meio da mobilização subjetiva o trabalhador transforma as situações causadoras de sofrimento no trabalho, lançando mão, para isso, de sua subjetividade, inteligência prática e do coletivo de trabalho (Mendes, 2007).

Além disso, deve-se mencionar a importância do reconhecimento no trabalho, pois este dará sentido ao esforço realizado pelo trabalhador na transformação da organização do trabalho. $\mathrm{O}$ reconhecimento pode ser de dois tipos: de utilidade e de beleza. O primeiro é referente àquele advindo dos clientes que avalia a qualidade técnica, social e econômica da contribuição do trabalhador, enquanto o segundo refere-se àquele realizado pelos pares para reconhecer a qualidade do trabalho executado pelo trabalhador (Dejours, 1999).

Prazer e sofrimento são, para a abordagem psicodinâmica do trabalho, conceitos inerentes ao trabalho, relacionados ao fluxo do processo psíquico do indivíduo, que é determinado pela realização ou repressão da energia psíquica na relação indivíduo-trabalho (Antloga \& Mendes, 2009).

Diante disso, para fins desta pesquisa, conforme será detalhado mais adiante, foram realizadas entrevistas junto aos pastores que permitiram conhecer a realidade deste trabalho e interpretar a relação entre o sujeito e sua situação de trabalho. Buscou-se, também, desvelar os mecanismos de defesa utilizados para enfrentar as situações geradoras de sofrimento e conhecer de que modo eles se mobilizam para enfrentar, satisfatoriamente, as situações que os fazem sofrer.

\section{Trabalho Pastoral}

Quanto às condições gerais de exercício da atividade pastoral, o Ministério do Trabalho e do Emprego (MTE) afirma que os profissionais podem desenvolver suas funções como consagrados ou leigos, de forma profissional, sendo remunerados pelo seu trabalho, ou de forma voluntária e sem remuneração, em templos, igrejas, (...) etc. Os pastores também estão presentes em universidades e escolas, centros de pesquisa, sociedades beneficentes e associações religiosas, organizações nãogovernamentais, instituições públicas e privadas (Ministério do Trabalho e Emprego, 2012).

\section{Materiais e método}

Esta pesquisa utilizou abordagem qualitativa para coleta e análise de dados oriundos de entrevistas semiestruturadas individuais. Em psicodinâmica do trabalho, 
a entrevista constitui-se uma técnica de coleta de dados que prioriza a escuta dos conteúdos manifestos e latentes dos sujeitos da pesquisa, considerando relevante a relação entre pesquisador e pesquisado. Suas questões não adotam um roteiro rigidamente prescrito, pois ao considerar como prioridade a escuta e a fala do sujeito, leva em conta a lógica subjetiva de seu discurso, na qual o pesquisador deve estar aberto para escutar o que está além de sua expectativa. A fala do entrevistado fornecerá conteúdos para a interpretação final (Mendes, 2007).O projeto desta pesquisa foi aprovado pelo Comitê de Ética em Pesquisa da Universidade Católica de Brasilia (CEP-UCB).

A amostra foi constituída por quinze pastores de Igrejas Evangélicas do Distrito Federal. Os critérios de inclusão foram: ser maior de idade, receber remuneração de suas igrejas, exercer a atividade pastoral no Distrito Federal a pelo menos dois anos e aceitar assinar o Termo de Consentimento Livre e Esclarecido concordando com a participação no estudo.

Elaborou-se um roteiro de entrevista semiestruturada a partir do referencial teórico adotado, contendo as seguintes questões: (1) Fale sobre seu trabalho; (2) O que te dá prazer no trabalho?; (3) O que você mais gosta no seu trabalho?; (4) O que lhe causa sofrimento no trabalho?; (5) $\mathrm{O}$ que você menos gosta?; (6) O que você faz para lidar com esse sofrimento? (estratégias de enfrentamento); (7) Você sente que é reconhecido no seu trabalho?; (8) Quais vivências são exemplos desse reconhecimento?; (9) Caso não haja reconhecimento: Como você enfrenta/lida com a falta de reconhecimento?; (10) Como você reage diante da falta de reconhecimento?; (11) Como você se sente depois de um dia de trabalho?; (12) Como o trabalho tem afetado seu comportamento e sua saúde?; e (13) Você se afastou das atividades pastorais, por problemas de saúde, nos últimos doze meses? Se sim, quantas vezes, e por qual motivo?

O procedimento de coleta de dados se deu por meio da realização de entrevis tas semiestruturadas individuais, com perguntas relacionadas aos objetivos propostos. As entrevistas foram gravadas em áudio e posteriormente transcritas. O tempo médio de duração das entrevistas foi de 50 minutos (variando entre 30 minutos e 1 hora e 10 minutos).As falas foram categorizadas por meio da técnica de Análise dos Núcleos de Sentido (ANS) proposta por Mendes (2007).

\section{Resultados}

Após agrupadas as transcrições das quinze entrevistas realizadas, chegou-se a um corpus total de 117 páginas de verbalizações e mais de 48.000 palavras. 
Os resultados da pesquisa foram agrupados em cinco núcleos de sentido, intitulados com uma verbalização extraída das entrevistas que descrevesse o conteúdo de cada um deles, a saber: (1) "Cuidar de pessoas, ouvir pessoas"; (2) "Se tem uma pessoa que é apaixonada pelo que faz, sou eu”; (3) “Às vezes é muito dificil, tá complicado"; (4) "Só entregando pra Deus mesmo"; e (5) "Tenho que enfrentar cansaço, estresse, dor de cabeça, mal estar".

\section{Núcleo de Sentido 1:“Cuidar de pessoas, ouvir pessoas"(Frequência: 66).}

Descrição do Núcleo de Sentido:As tarefas desempenhas pelos pastores são: pregar (discursar durante os cultos), ensinar (oferecer cursos), aconselhar (ouvir demandas e sugerir soluções), evangelizar (discursar fora da igreja com a intenção de atrair novos membros), visitar (realizar visitas domiciliares), adorar (entoar canções religiosas) e orar (dedicar-se à oração). Quase a totalidade dos entrevistados relatou a existência de sobrecarga de trabalho. Segundo os pastores, está é considerada "uma das funções mais estressantes da face da terra”. A maioria afirma que está fisicamente cansada, visto que o trabalho "é uma maratona" que leva, inclusive, ao desenvolvimento de doenças. Os pastores também mencionam haver uma exigência excessiva em relação ao fato que thes é demandado estar disponível em tempo integral para atender os fiéis sempre que os mesmos necessitarem.

Os temas que compõem este núcleo de sentido serão apresentados na Tabela a seguir:

Tabela 1 - "Cuidar de pessoas. ouvir pessoas. É isso o que eu faco".

\begin{tabular}{|l|c|}
\hline \multicolumn{1}{|c|}{ Temas } & Frequência \\
\hline Tarefas realizadas & 39 \\
\hline Excesso de trabalho & 16 \\
\hline Disponibilidade constante & 11 \\
\hline Total de verbalizações & $\mathbf{6 6}$ \\
\hline
\end{tabular}

Fonte: pesquisa do autor.

Exemplos de Verbalizações:

$\checkmark$ "Nós lidamos 24 horas com o ser humano e seus problemas".

$\checkmark \quad$ "Tem dia que é muito cansativo, fico tão cansado que só quero dormir". $\checkmark$ "O trabalho é cansativo e ele suga as energias".

$\checkmark$ "Temos que sair, compartilhar corpo a corpo, anunciar o reino de Deus". 
$\checkmark$ "A pregação do evangelho faz parte do meu trabalho".

$\checkmark$ "Eu trabalho com a Escola Bíblica Dominical".

$\checkmark$ "Cuidar de pessoas, ouvir pessoas. É isso o que eu faço".

\section{Núcleo de Sentido 2:"Esse trabalho realmente é a coisa mais maravilhosa do mundo". (Frequência: 33).}

Descrição do Núcleo de Sentido:Quase todos os pastores afirmam que gostam muito do que fazem e se identificam com a maior parte das tarefas, tais como pregar, ensinar, visitar, evangelizar, aconselhar, orar e adorar. A maior parte dos entrevistados considera ser importante seu trabalho de converter, restaurar, curar $\mathrm{e}$ transformar pessoas, pois consideram que uma das maiores alegrias do trabalho pastoral é "ver a transformação de vida". Parte deles acredita que há reconhecimento de utilidade do seu trabalho por parte dos fiéis que frequentam sua igreja, o que thes é demonstrado por meio de agradecimentos, presentes e homenagens em datas especiais. Um terço dos participantes comenta que sente muita satisfação e realização pessoal no exercício de suas atividades pastorais são completamente apaixonados pelo que fazem, pois "esse trabalho é a coisa mais maravilhosa do mundo". Um entrevistado credita importância ao trabalho pastoral no que tange à aceitação dos ensinamentos religiosos por parte dos fiéis, o que se demonstra quando estes "compreendem e praticam aquilo que está sendo ensinado".

Tabela 2 - "Esse trabalho realmente é a coisa mais maravilhosa do mundo".

\begin{tabular}{|l|c|}
\hline \multicolumn{1}{|c|}{ Temas } & Frequência \\
\hline $\begin{array}{l}\text { Identificação com as Tarefas (pregar, ensinar, visitar, evangelizar, } \\
\text { aconselhamento, adoração e oração) }\end{array}$ & 13 \\
\hline $\begin{array}{l}\text { Conversão, Restauração, Curas e Transformação são atividades } \\
\text { importantes. }\end{array}$ & 08 \\
\hline Reconhecimento de Utilidade do trabalho pastoral pelos fiéis & 06 \\
\hline Satisfação e Realização Pessoal & 05 \\
\hline $\begin{array}{l}\text { A aceitação de seus ensinamentos pelos fiéis revela a importância do } \\
\text { trabalho pastoral. }\end{array}$ & 01 \\
\hline Total de verbalizações & $\mathbf{3 3}$ \\
\hline
\end{tabular}

Fonte: pesquisa do autor

Exemplos de Verbalizações: 
$\checkmark \quad$ "O que eu mais gosto de fazer é pregar a Palavra de Deus".

$\checkmark$ 'Eu sou muito feliz como pastor, me sinto realizado".

$\checkmark$ "Se tem uma pessoa que é apaixonada pelo que faz, sou eu".

$\checkmark$ 'É bom ver as almas sendo rendidas aos pés do Senhor".

$\checkmark$ "Trabalhar com cura e libertação dá muito prazer".

"A vida pastoral me dá contentamento ao lidar com pessoas. É muito gostoso ser útil".

$\checkmark$ "Esse trabalho realmente é a coisa mais maravilhosa do mundo".

\section{Núcleo de Sentido 3:“Às vezes é muito difícil, tá complicado"(Frequência: 44).}

Descrição do Núcleo de Sentido:A maioria dos entrevistados demonstra falta de identificação com algumas tarefas pastorais, tais como visitar presídios, cuidar de questões administrativas e ter que disciplinar ou excluir algum membro da comunidade quando isso se faz necessário.
Quase metade da amostra revelou que o trabalho pastoral em alguns momentos gera sentimentos como ingratidão, impotência, solidão, decepção e tristeza. Aproximadamente metade da amostra acredita que o discurso pastoral, que é considerado por eles a sua principal ferramenta de trabalho, é insuficiente para fazê-los alcançar os propósitos da igreja, e que o fato de fiéis não seguirem suas instruções constitui-se fonte de sofrimento no trabalho. Quatro pastores mencionam haver falta de reconhecimento no trabalho por parte dos fiéis e dizem que quando isso ocorre sentem-se feridos, às vezes choram e ficam muito tristes. Um pequeno grupo de entrevistados também menciona cansaço psíquico, que se associa a um desejo de desistir da profissão, já que a mesma "suga as energias", levando-os à estafa.

Os temas que compõem este núcleo de sentido serão apresentados na Tabela a seguir:

Tabela 3 - "Às vezes é muito difícil, tá complicado".

\begin{tabular}{|l|c|}
\hline \multicolumn{1}{|c|}{ Temas } & Frequência \\
\hline Cansaço físico & 11 \\
\hline Falta de identificação com a tarefa & 08 \\
\hline Sentimentos negativos em relação ao trabalho & 07 \\
\hline Insuficiência do discurso pastoral & 07 \\
\hline Falta de reconhecimento do trabalho pastoral & 05 \\
\hline Cansaço psíquico & 04 \\
\hline
\end{tabular}




\section{Total de verbalizações}

44

Fonte: pesquisa do autor.

Exemplos de Verbalizações:

"Deus tem a hora certa de realizar a vontade

"Humanamente falando, a gente fica triste, a gente se abate".

$\checkmark$ "A gente fica chateado pelo fato da pessoa ouvir [o discurso pastoral] e não tomar uma atitude".

$\checkmark$ "Falta de reconhecimento, decepção e angústia é parte do nosso trabalho".

$\checkmark$ “O trabalho suga as energias e às vezes dá certa estafa".

\section{Núcleo de Sentido 4: "Só entregando pra}

Deus mesmo" - (Frequência: 35).

Descrição do Núcleo de Sentido:Como forma de enfrentamento dos problemas gerados pelo trabalho pastoral, a maior parte dos entrevistados disse recorrer à oração, considerada por eles "a chave de tudo". Manifestam que acreditar em uma gratificação futura, em "uma vida vindoura, prometida por Jesus, é a maior recompensa". A crença na onipotência divina é expressa quando afirmam que
Dele". Alguns buscam terapias e lazer para aliviar as tensões do trabalho, enquanto outros buscam realizar atividades físicas, tais como passeios e caminhadas. Um terço da amostra revelou que lida com os problemas buscando pessoas com quem possam conversar sobre seu trabalho, podendo ser outros pastores ou até mesmo familiares. Três participantes afirmam lidar com os problemas "muito naturalmente", já que as dificuldades fazem parte do trabalho e que cada um deve se preocupar em cumprir suas responsabilidades. Um pastor ainda investe na capacitação de terceiros para que possam ser seus auxiliares nas tarefas que menos gosta de exercer enquanto outro, diante dos problemas, se esforça ainda mais para realizar aquela atividade, já que acredita que é o seu esforço o que irá impactar positivamente na solução do problema.

Tabela 4 - "Só entregando pra Deus mesmo"

\begin{tabular}{|l|c|}
\hline \multicolumn{1}{|c|}{ Temas } & Frequência \\
\hline Pedir ajuda a Deus para lidar com as dificuldades & 09 \\
\hline Acreditar em uma recompensa divina futura & 09 \\
\hline Buscar terapias e lazer & 08 \\
\hline Dialogar com terceiros & 07 \\
\hline Afirmar que as dificuldades fazem parte do trabalho & 04 \\
\hline
\end{tabular}




\begin{tabular}{|l|c|}
\hline $\begin{array}{l}\text { Treinamento de pessoas para lhes auxiliar em tarefas com as quais } \\
\text { não se identificam }\end{array}$ & 01 \\
\hline Empreender mais esforço e dedicação nas tarefas & 01 \\
\hline Total de verbalizações & $\mathbf{3 9}$ \\
\hline
\end{tabular}

Fonte: pesquisa do autor

Exemplos de Verbalizações:

$\checkmark$ "Minha estratégia é descansar em Deus, orar, buscar refúgio em Deus".

$\checkmark$ 'Nosso reconhecimento não vai ser aqui".

$\checkmark$ "Por Deus você é recompensado".

$\checkmark$ "O acompanhamento profissional tem me ajudado".

$\checkmark$ “Às vezes a gente conversa com outro pastor amigo".

$\checkmark$ "Minha esposa, às vezes, acaba sendo um para-raios".

$\checkmark$ "Só entregando pra Deus mesmo".

Núcleo de Sentido 5:"Tenho que enfrentar cansaço, estresse, dor de cabeça, mal estar"(Frequência: 10).
Descrição do Núcleo de Sentido: Alguns entrevistados acreditam que a presença de danos físicos como pressão alta, insônia, dores na coluna, dores de cabeça, crises alérgicas, renite e arritmia são resultantes da atividade pastoral. Outros relacionaram ao seu trabalho a existência dedanos psíquicos, tais como estresse emocional, choro, depressão, desânimo e esgotamento mental. Ainda foi relatada a presença de danos sociais ligados ao trabalho, tais como sentimentos de solidão, problemas no convívio familiar e alterações na relação com a família.

Os temas que compõem este núcleo de sentido serão apresentados na Tabela a seguir:

Tabela 5 - Tenho que enfrentar cansaco, estresse, dor de cabeca, mal estar.

\begin{tabular}{|l|c|}
\hline \multicolumn{1}{|c|}{ Temas } & Frequência \\
\hline Danos Físicos & 04 \\
\hline Danos Psíquicos & 03 \\
\hline Danos Sociais & 03 \\
\hline Total de verbalizações & $\mathbf{1 0}$ \\
\hline
\end{tabular}

Fonte: pesquisa do autor.

Exemplos de Verbalizações:

$\checkmark$ "Tenho que enfrentar cansaço, estresse, dor de cabeça, mal-estar". $\checkmark$ 'Fiquei com pressão alta, problema de sono - acho que é nervosismo". 
"Muitas vezes eu tenho que chorar o dia inteiro, a noite inteira, três dias [para lidar com as questões psíquicas relativas ao trabalho]".

"Às vezes o trabalho acaba alterando a relação com a família".

\section{Discussão e conclusões}

Os resultados apresentam cinco núcleos de sentido, cujo assunto principal, refere-se, respectivamente, aos seguintes tópicos da abordagem Psicodinâmica do Trabalho, a saber: (1) organização do trabalho; (2) Vivências de prazer no trabalho; (3) Vivências de sofrimento no trabalho; (4) Estratégias de mediação do sofrimento; e (5) Adoecimento relacionado ao trabalho.

Prazer e sofrimento são, para a abordagem psicodinâmica do trabalho, conceitos inerentes ao trabalho, relacionados ao fluxo do processo psíquico do indivíduo, que é determinado pela realização ou repressão da energia psíquica na relação indivíduo-trabalho (Antloga \&Mendes, 2009). Isso foi evidenciado nas falas dos pastores entrevistados, pois relatam intenso prazer no desenvolvimento de suas atividades pastorais, a despeito de diversas situações geradoras de sofrimento, corroborando com a afirmativa de que prazer e sofrimento não podem ser totalmente eliminados desse processo (Dejours, 2004).
As vivências de prazer surgem quando as exigências intelectuais, motoras ou psicossensoriais da tarefa convergem para a satisfação das necessidades do trabalhador, de tal modo que a simples execução da atividade proporcione prazer (Dejours, 1994). Nesta pesquisa, essa satisfação ficou evidenciada no núcleo de sentido "Eu gosto do que faço". Os temas ligados às vivências de prazer relacionamse com o fato dos pastores se sentirem identificados com a tarefa, o que eleva seus índices de satisfação e os realiza profissionalmente. Os pastores se sentem muito felizes e gratos por desempenhare $m$ sua tarefa e quando notam que seu trabalho impacta positivamente a vida daqueles que são assistidos em sua igreja. A identificação com a tarefa é um indicador de sentimento de realização profissional (Mendes, 2007). Poucas foram as atividades que desempenham que não geram vivências de prazer no trabalho.

Outro aspecto importante que se relaciona às vivências de prazer é o reconhecimento. Para alcançá-lo, os trabalhadores devem estar inseridos em um ambiente que promova o reconhecimento e a valorização do trabalho, uma vez que, dessa forma, é possível obter satisfação das necessidades do trabalhador (Ferreira \& Mendes, 2003). Estudos confirmam que a falta de reconhecimento da profissão ou do trabalho é fonte de sofrimento psíquico e 
que a dinâmica do reconhecimento como fonte de prazer origina-se a partir dos pares, hierarquia, clientes/usuários ou amigos e familiares (Mendes \& Morrone, 2010). No caso dos pastores, especificamente, acrescentam-se a esta lista os fiéis, membros e frequentadores da igreja.

Ressalta-se que foi perguntado diretamente aos pastores se os mesmos se sentem reconhecidos por seu trabalho. Como resultados, tem-se que todos eles se dizem reconhecidos. No entanto, ao se considerar a noção de reconhecimento dada pela Psicodinâmica do Trabalho, não se pode afirmar que a totalidade dos entrevistados experienciam, de fato, o reconhecimento. No núcleo de sentido sobre as vivências de sofrimento no trabalho, inclusive, um dos temas relacionase à falta de reconhecimento do trabalho pastoral, o que indica uma contradição no discurso dos entrevistados. Muitas vezes, afirmar a existência do reconhecimento significa que o que está presente é apenas o auto-reconhecimento, com negação do olhar do outro em relação à qualidade ou utilidade do trabalho, o que está mais ligado, portanto, à sua identificação com a tarefa do que ao reconhecimento propriamente dito. Afirmar que ajudar os outros proporciona contentamento pode ser um discurso defensivo, justamente frente à falta de reconhecimento do fiel à ajuda prestada.
O processo de valorização do esforço e do sofrimento investido para a realização do trabalho possibilita ao sujeito a construção de sua identidade, traduzida afetivamente por vivência de prazer, satisfação pessoal e realização de si mesmo (Mendes, 2007). Nesta pesquisa, tem-se que satisfação e realização pessoal estão fortemente presentes nas falas dos entrevistados, os quais afirmaram que são muito felizes como pastores, pessoas apaixonadas pelo que fazem, chegando a considerar o seu trabalho "a coisa mais maravilhosa do mundo".

A importância social do trabalho pastoral como fonte de prazer também está presente no discurso dos entrevistados, em especial quando mencionam que trabalhar com curas, libertação, conversões e "salvação" de dependentes químicos traz muito prazer. Além dessas ações, foi comentado que atender as pessoas que passam por alguma necessidade básica (como falta de alimentos, gás, dinheiro) ou ajudar casais em conflito na restauração do convívio familiar é algo muito gratificante e representa a parte social do trabalho pastoral. O trabalho assume um sentido positivo quando é realizado de forma eficiente para si e para a sociedade (Morin, 2001 apud Silva, 2004).

Como já foi mencionado, segundo a psicodinâmica do trabalho, o trabalho pode não apenas proporcionar prazer e satisfação 
ao sujeito, mas se apresenta, ao mesmo tempo, como fonte de angústia e sofrimento, o que também é demonstrado por esta pesquisa (Mendes \& Morrone, 2010). Ainda segundo as autoras, como fontes de sofrimento mais explícitas estão a sobrecarga de trabalho, a exigência de estarem sempre disponíveis e os cansaços físico e psíquico, que estabelece que alguns dos fatores determinantes de vivências de sofrimento no trabalho são a sobrecarga, o excesso de trabalho, as longas jornadas de trabalho e a insuficiência de pausa e repouso relacionados às condições de trabalho.

No que se refere ao excesso de trabalho e à exigência de estarem sempre disponíveis, os entrevistados relatam que "pastor trabalha em tempo integral, tem que estar conectado às necessidades que surgirem, não importando o horário", o que faz referência ao fato de que, às vezes, os pastores são solicitados a atuar no meio da madrugada e que atender àqueles que os buscam, mesmo nesse período, configura-se uma necessidade. Segundo eles, há dias em que se sentem tão atarefados que mal conseguem fazer pausas para beber água e se alimentar corretamente. Além disso, é importante destacar que os pastores consideram que as atividades pastorais não acabam quando eles retornam para suas casas após um dia de trabalho, visto não conseguirem se desligar dos problemas ao final do expediente. Em seus momentos de pausa, os pastores entrevistados continuam refletindo sobre os problemas em busca de soluções, o que encontra respaldo na teoria utilizada, pois o período de trabalho não se limita ao tempo que se passa no ambiente de trabalho - ao contrário, ultrapassa qualquer limite de tempo, mobilizando a personalidade do trabalhador por completo mesmo fora do local onde este é realizado (Dejours, 2004).

Como resultado da sobrecarga de atividades, os pastores mencionam sentir intenso cansaço físico e afirmam que, algumas vezes, ao fim de um dia de trabalho, estão completamente esgotados, pois o trabalho pastoral, além de ser uma maratona, é cansativo e suga todas as suas energias. O cansaço psíquico também foi explicitado pelos pastores, já que às vezes os mesmos se sentem completamente desanimados, "para baixo", esgotados quase a ponto de sofrerem uma estafa, quererem fugir, ir embora e desistir de tudo.

Ainda a respeito de fontes de sofrimento no exercício do trabalho pastoral, foi possível perceber a presença de danos físicos, psíquicos e sociais, os quais, de acordo com a teoria, são provocados pelo confronto do trabalhador com determinados contextos de trabalho (Ferreira \& Mendes, 2003). Segundo os autores, esses contextos são aqueles que provocam dores no corpo e distúrbios biológicos (danos físicos); percepção negativa de si mesmo e 
alterações de humor (danos psíquicos); e isolamento e dificuldades nas relações familiares e sociais (danos sociais). Cansaço, pressão alta, arritmia, problemas de sono, dores na coluna, dores de cabeça, crises de renite e alergias são alguns dos danos físicos relacionados às atividades pastorais dos entrevistados. Já os danos psíquicos encontrados na pesquisa referemse à presença de estresse emocional, vontade constante de chorar, tristeza profunda, decepção e angústia. Como danos sociais foram destacados sentimentos de solidão, irritabilidade e distanciamento dos familiares e amigos.

O uso de estratégias de mediação do sofrimento se faz necessário para que o trabalhador enfrente as adversidades relacionadas ao seu trabalho, podendo ser essas o uso de defesas ou a mobilização subjetiva. Essas estratégias, se bem utilizadas, evitam o adoecimento do trabalhador em contextos organizacionais adversos. Caso sua utilização não seja bem sucedida e as estratégias para lidar com o sofrimento falhem, e/ou quando o trabalhador não tem oportunidade de mudar a organização ou condições de trabalho que provocam sofrimento, ocorre o adoecimento (Antloga \& Mendes, 2009). Quando expostos ao sofrimento no trabalho, os sujeitos podem desenvolver estratégias defensivas individuais ou coletivas, que servem de mecanismos promotores de negação e evitação das experiências dolorosas e, assim, se protegem do sofrimento suscitado pelas pressões da organização ou condições de trabalho (Ferreira \& Mendes, 2003). No caso dos pastores entrevistados, pode-se verificar apenas a utilização de estratégias de defesa, estando ausente do discurso dos participantes o uso de mobilização subjetiva.

As estratégias de defesa, durante certo tempo, têm o papel de proteger o ego de sentimentos negativos contrários e afetos dolorosos (Ferreira \& Mendes, 2003). Neste estudo, diante da falta de reconhecimento por parte de alguns fiéis, membros ou frequentadores da igreja, os pastores lançam mão de uma estratégia defensiva particular, a racionalização, definida como "a evitação e a eufemização da angústia, do medo e da insegurança vivenciada no trabalho" (Ferreira \& Mendes, 2003, pág. 57)e relaciona-se à invocação de 'justificativas 'mágicas' socialmente valorizadas e causas externas para explicar situações de trabalho desconfortáveis" (Ferreira \& Mendes, 2003, pág. 57).

$\mathrm{Na}$ pesquisa, essa defesa se associa ao fato dos pastores acreditarem que o verdadeiro reconhecimento não é passível de se experienciar na vida terrena, mas o será apenas em "outro plano" e somente poderá ser dado por Deus, a quem afirmam estar servindo. Esse tipo de reconhecimento 
não pode ser enquadrado nos tipos de reconhecimentos clássicos da teoria estudada (utilidade e beleza), visto que essa entidade não pode ser considerada como pertencendo à mesma hierarquia/posição que colegas de trabalho, clientes, fornecedores ou chefias. Estudos futuros a respeito desta temática devem ser desenvolvidos para que se possa compreender de forma mais aprofundada a importância da crença desses profissiona is no reconhecimento divino como constituinte da saúde dos pastores, incluindo a possibilidade disso poder leválos a desenvolver outros tipos de defesa, como a auto-aceleração. Ainda, mereceria ser investigado se essa crença conduz à servidão voluntária. Dada a natureza desta pesquisa, tais associações não puderam ser realizadas.

Ainda a respeito do uso da racionalização, que é caracterizada por comportamentos de apatia, resignação, indiferença e passividade (Ferreira \& Mendes, 2003), deve-se evidenciar que os pastores dizem lidar com os problemas de forma "natural", pois sabem que essas coisas "são assim mesmo" e fazem parte da vida de qualquer trabalhador.

Estratégias defensivas são regras de condutas construídas e conduzidas pelos trabalhadores que variam de acordo com as situações de trabalho, sendo as mesmas marcadas pela sutileza, engenhosidade, diversidade e inventabilidade, capazes de fazer com que os trabalhadores suportem o sofrimento sem adoecer (Dejours, 1994). Nesta pesquisa, verificou-se que os entrevistados utilizama religiosidade na tentativa de minimizar o sofrimento, pois diante das situações adversas e problemas decorrentes das atividades pastorais, afirmam colocar sua fé em prática e confiar na palavra de Deus. Também foram mencionadas como estratégias para mediar esse sofrimento a oração, o jejum, os pedidos para que Deus os mostre uma direção e a espera confiante na interve nção divina como forma de retribuição por seu esforço. A utilização adequada dessa estratégia de defesa, especificamente, pode justificar o fato de que, apesar da existência das adversidades no trabalho pastoral, nem todos os entrevistados chegam a adoecer.

Para os pastores, a religiosidade é tida como uma forma para lidar com o sofrimento vivido nas atividades pastorais. Além de derivar de preceitos bíblicos, próprios do cristianismo, orar, jejuar, confiar e retirar-se espiritualmente são formas encontradas para aliviar as tensões do seu trabalho pastoral, o que corrobora os achados de Silva (2004). A religiosidade, que é definida como a busca humana do sagrado, do divino, do transcendente - algo inerente à própria atividade pastoral - tem a função de proteger o ego do pastor, mas, ao mesmo tempo, também pode aliená-lo 
(Siqueira apud Silva, 2004). Nesse sentido, apesar dos entrevistados terem manifestado que a oração soluciona os problemas que vivem em seu trabalho, ela não é capaz de modificar a organização do trabalho, e, por essa razão, é aqui considerada uma estratégia de defesa, e não mobilização subjetiva. $\mathrm{Na}$ concepção dos pastores, buscar refúgio em Deus é a principal ferramenta que possuem para mudar a realidade, pois segundo os mesmos, a “oração é a chave de tudo". Uma análise superficial desse dado poderia levar a um equívoco de interpretação, visto que, aparentemente, a oração poderia ser considerada mobilizadora, e não uma defesa. Isso conduz a uma crítica ao trabalho de Silva (2004), que aponta a religiosidade (oração) como uma das principais alternativas que os pastores possuem para lidar com as frustrações, os desgastes, os medos e as angústias da vida pastoral, subsidiando, assim, sua integridade física, psíquica e social.

A busca por atividades terapêuticas, consultas psicológicas, boa alimentação, práticas esportivas e de outras atividades físicas periódicas são outros tipos de defesas utilizadas pelos trabalhadores, bem como a busca pelo coletivo, pois afirmam que, muitas vezes, nos momentos de dificuldades, procuram por outros pastores para compartilhar seus problemas. Houve relato de participação em reuniões semanais denominadas "pastoreio de pastores", onde podem ajudar-se mutuamente a suportarem as dificuldades. O que se pôde perceber, no entanto, é que esses encontros não permitem a modificação da organização do trabalho em termos dos principais focos de sofrimento, que são a sobrecarga de trabalho e a falta de reconhecimento.

Apesar da ausência de afastamentos médicos nos últimos doze meses, alguns pastores relatam estar adoecidos por seu trabalho, o que merece atenção especial, em termos das três dimensões humanas, os aspectos físico, psíquico e social. Outros estudos devem ainda ser realizados para que se possam compreender mais profundamente quais aspectos da atividade pastoral geram mais desgaste e danos ao trabalhador, de modo que seja possível prever formas de agir sobre os mesmos, tanto depois de terem se manifestado, como também anteriormente à sua existência, em caráter preventivo.

$O$ fato de se sentirem realizados como pastores não é razão suficiente para que intervenções diretas sobre essa população deixem de ser propostas. Esperase que este trabalho possa contribuir para a reflexão sobre a atividade pastoral de forma que intervenções possam ser sugeridas a fim de minimizar as vivências de sofrimento patogênico dos pastores, tornando, assim, essa atividade cada vez mais prazerosa e promotora de saúde a esses trabalhadores. 


\section{Considerações finais}

Espera-se que esta pesquisa tenha contribuído para a compreensão das vivências de prazer e sofrimento do trabalho pastoral, bem como das estratégias de mediação utilizadas pelos pastores para minimizar as fontes de sofrimento de sua atividade profissional. Além disso, acreditase que a ampliação da bibliografia sobre o assunto é também outra contribuição relevante, visto que existem poucos estudos científicos desenvolvidos no país com essa categoria.Como referencial teóricometodológico de compreensão da interrelação trabalho e saúde, a Psicodinâmica do Trabalho mostrou-se uma ferramenta útil para realização desta pesquisa, principalmente pelo fato de conter, dentre seus construtos, conceitos fundamentais para nortear trabalhos dessa natureza.

O presente trabalho foi de natureza exploratória, de caráter descritivo, não podendo generalizar-se para a realidade brasileira. No entanto, mesmo assim, acredita-se que o mesmo tenha sido capaz de salientar diversos temas que podem ser explorados de forma mais profunda futuramente. Ressalta-se, ainda, que os dados apresentados na pesquisa não pretendem esgotar a temática da Psicodinâmica do Trabalho aplicada à compreensão das vivências de prazer e sofrimentos experienciadas pelos pastores evangélicos no exercício de suas atividades pastorais. Ao contrário, o presente estudo intencionou abrir esse campo para a possibilidade de se realizarem novos estudos que contem com a participação de uma amostra mais significativa, visto que, se considerado o universo de mais de 3000 pastores que atuam no Distrito Federal, este estudo é ainda incipiente para a compreensão das vivências de prazersofrimento desses profissionais.

A descrição desta organização do trabalho pode ter sido comprometida pelo fato dos entrevistados não realizarem suas atividades em um mesmo contexto de trabalho. Apesar disso, pode-se perceber que há considerável similaridade entre o que relatam a respeito de sua jornada de trabalho, ritmo, tempo para realização das tarefas e, inclusive, as fontes de sofrimento encontradas. Outra questão singular nesta pesquisa foi a ausência de um coletivo de trabalho que atue no mesmo contexto profissional, visto que apenas o pastor é responsável e atua em sua igreja. Há de se considerar, ainda, um possível viés nesse estudo, que é o fato do pesquisador ser pastor evangélico. Para minimizar potenciais interferências em razão deste fato, tomou-se o cuidado de se entrevistar apenas voluntários que fossem completamente desconhecidos do autor. Cabe, porém, ressaltar, que esse envolvimento com a atividade trouxe, por 
outro lado, duas vantagens que merecem ser destacadas: (1) uma maior facilidade de contato com a entidade representativa desse seguimento (a fim de conseguir a autorização necessária para a realização deste trabalho); e (2) uma melhor comunicação com os entrevistados, pelo fato do pesquisador conhecer as especificidades do trabalho pastoral e compreender melhor a linguagem utilizada pelos entrevistados. Esse viés foi ainda reduzido quando se decidiu por analisar os

\section{Refefências}

Antogla, C. S. \&Mendes, A. M. (2009). Sofrimento e adoecimento dos vendedores de uma empresa de material de construção. Psicologia: Teoria e Pesquisa25(2): 255-262.

Ministério do Trabalho e Emprego (2012). Classificação Brasileira de Ocupações. Brasîlia.

Dejours, C. (1992). A loucura do Trabalho: estudo de psicopatologia do trabalho.São Paulo: Cortez.

Dejours, C; Abdoucheli, E; \& Jayet, C. (1994). Psicodinâmica do trabalho: contribuições da escola dejouriana à análise da relação prazer, sofrimento e trabalho. São Paulo: Atlas.

Dejours, C. (1996). Uma nova visão do sofrimento humano nas organizações. In Chanlat, J. $O$ indivíduo na organização. Dimensões esquecidas. São Paulo: Atlas.

Dejours, C. (1999). Conferências Brasileiras: identidade, reconhecimento e transgressão no trabalho. São Paulo: FUNDAP. dados sempre com três juízes - além do aluno pesquisador, assumiram essa função a professora orientadora e outra pesquisadora com experiência na condução de pesquisa em psicodinâmica do trabalho.

Um benefício do estudo para os entrevistados será a disponibilização da versão eletrônica do trabalho aos pastores que informaram seu e-mail ao pesquisador com essa finalidade e manifestaram interesse em receber uma devolutiva dos resultados da pesquisa.

Dejours, C. (2004). O trabalho como enigma. In: Lancman, S.\&Sznelwar, L. V. (Orgs.). Christophe Dejours: Da psicopatologia à psicodinâmica do trabalho. Rio de Janeiro: Editora Fiocruz, Brasilia: Paralelo 15.

Ferreira, M. C. \& Mendes, A. M. (2003). Trabalho e risco de adoecimento: o caso dos auditores-fiscais $d a$ Previdência Social brasileira. Brasília: Ler, Pensar, Agir.

Freitas, L, G. (2006). Saúde e Processo de Adoecimento do Trabalho (Tese de Doutorado). Programa de PósGraduação em Psicologia Social e do Trabalho - Universidade de Brasília, Brasîlia, DF, Brasil.

Instituto Brasileiro de Geografia e Estatística (1992). Censo demográfico de 1991. Rio de Janeiro: IBGE.

Instituto Brasileiro de Geografia e Estatística (2003). Censo demográfico de 2000. Rio de Janeiro: IBGE.

Instituto Brasileiro de Geografia e Estatística (2012). Censo demográfico de 2010. Rio de Janeiro: IBGE. 
Mendes, A. M. B (1994). Prazer $e$ Sofrimento no Trabalho Qualificado: em um estudo exploratório com engenheiros de uma empresa pública de Telecomunicações (Dissertação de Mestrado). Programa de PósGraduação em Psicologia Social e do Trabalho. Universidade de Brasília, Brasília, DF, Brasil.

Mendes, A. M. (2007). Psicodinâmica do trabalho: teoria, métodos e pesquisas. São Paulo: Casa do Psicólogo.

Mendes; A. M. \& Morrone, C. (2010). Trajetória teórica e pesquisas brasileiras sobre prazer e sofrimento no trabalho. In: Mendes, A. M.; Merlo, A. R. C; Morrone, C. F. \& Facas, E. P. Psicodinâmica e clínica do trabalho: temas, interfaces e casos brasileiros. Curitiba: Juruá.

Ministério do Trabalho e Emprego (2002). Classificação Brasileira de Ocupações: CBO 2002. Brasîlia: MTE.

Silva, R. R. (2004). Profissão pastor: prazer e sofrimento: uma análise psicodinâmica do trabalho de líderes religiosos neopentecostais $e$ tradicionais (Dissertação de mestrado). Programa de Pós-Graduação em Psicologia Social e do Trabalho. Universidade de Brasilia, Brasilia, DF, Brasil.

Weber, M. (1967). A ética protestante e o espírito do capitalismo. São Paulo: Pioneira.

\section{Data de Submissão: 01/08/2018}

Data de Aceite: 30/10/2018 